\title{
Effect of Body Weight on Age at Onset in Huntington Disease
}

A Mendelian Randomization Study

Jorien M.M. van der Burg, MD, PhD, Patrick Weydt, MD, PhD, Georg Bernhard Landwehrmeyer, MD, PhD, and N. Ahmad Aziz, MD, PhD

Neurol Genet 2021;7:e603. doi:10.1212/NXG.0000000000000603

\author{
Correspondence \\ Dr. Aziz \\ ahmad.aziz@dzne.de
}

\begin{abstract}
\section{Objective}

Weight loss is associated with clinical progression in Huntington disease (HD), but whether body weight causally affects disease onset or progression is unknown. Therefore, we aimed to assess whether genetically determined variations in body weight are causally related to age at onset in HD.
\end{abstract}

\section{Methods}

Using data from different recent genome-wide association studies, we performed a 2-sample mendelian randomization (MR) analysis to assess whether genetic markers of body mass index (BMI) are causally related to residual age at onset in $\mathrm{HD}$, i.e., the difference between observed and expected age at onset based on mutation size. Our study had a statistical power of $90 \%$ to detect a causal effect of $\geq 3.8$ months per BMI unit change at a type I error rate of 0.05 .

\section{Results}

Inverse-variance weighted MR estimates showed that a higher genetically determined BMI was not causally related to residual age at onset in $\mathrm{HD}(\beta=-0.44$ years per unit increase in $\mathrm{BMI}$, confidence interval: -1.33 to $0.46, p=0.34$ ). All other complementary (nonparametric) MR regression methods yielded similar results.

\section{Conclusions}

Although maintaining a healthy and stable body weight remains important in patients with HD, promoting weight gain with the aim of delaying disease onset or slowing down disease progression should be discouraged. Our findings point toward the existence of underlying pathologic processes that dictate both the rate of clinical progression and weight loss in $\mathrm{HD}$, which need further elucidation as targeting these pathways, rather than body weight per se, could be of therapeutic value. 


\section{Glossary}

BMI = body mass index; CI = confidence interval; GeM-HD = Genetic Modifiers of Huntington Disease; GIANT = Genetic Investigation of Anthropometric Traits; GWAS = genome-wide association study; HD = Huntington disease; MR = mendelian randomization; MR-PRESSO = MR pleiotropy residual sum and outlier; SNP = single nucleotide polymorphism.

Unintended weight loss is a hallmark of Huntington disease (HD), an autosomal dominant inherited neurodegenerative disorder caused by a CAG repeat expansion in the HTT gene, and occurs in both patients and premanifest mutation carriers, as well as many genetic animal models of the disease. ${ }^{1,2}$ Recently, we found that body weight is a robust predictor of the rate of clinical progression in patients with $\mathrm{HD} .^{3}$ Patients with a higher body mass index (BMI) at their first visit deteriorated more slowly in the motor, cognitive, and functional domains, independent of disease severity at baseline and mutant CAG repeat size. ${ }^{3}$ However, given that these findings were based on observational data, it remains to be clarified whether a higher body weight slows down disease progression, or alternatively, should be regarded as an epiphenomenon (i.e., a marker of slow disease progression without affecting the underlying pathologic processes). Elucidating this question is of critical importance as, in the first instance, measures to increase body weight would be expected to decrease the rate of deterioration in $\mathrm{HD}$, whereas in the latter instance, search for the mechanisms that underlie weight loss in $\mathrm{HD}$ should be continued as targeting these mechanisms, rather than body weight per se, could be of therapeutic relevance. To address this issue, here we applied mendelian randomization (MR), a method to explore causal effects based on genetic instrumental variables, to assess the directionality of effect between BMI and age at onset, which could also be regarded as a proxy for disease progression, in $\mathrm{HD}$.

\section{Methods}

\section{Two-Sample Mendelian Randomization}

We performed a 2-sample MR study-a statistical method that allows the exploration of the causal effects of an exposure (here BMI) on an outcome (here residual age at onset) by combining summary statistics from genome-wide association studies (GWASs) performed in different populations. ${ }^{4} \mathrm{We}$ specifically assessed whether single nucleotide polymorphisms (SNPs) that have been associated with BMI were also associated with residual age at onset in $\mathrm{HD}$, assuming unconfounded effects of these genetic instruments on the outcome mediated through BMI. ${ }^{4}$

\section{GWAS Summary Statistics for BMI}

As genetic instrumental variables for BMI, we selected SNPs from the combined summary statistic files of the 2 largest genetic association studies of body weight available to date (i.e., the GWAS meta-analysis of the Genetic Investigation of Anthropometric Traits (GIANT) consortium and the UK BioBank study), based on combined data from $\sim 700,000$ individuals. ${ }^{5,6}$ A clumping procedure was performed to retain the index SNPs that were independently related to BMI at a genome-wide significance level of $p<5 \times 10^{-8}$. SNPs that were in linkage disequilibrium with the index SNPs $\left(R^{2}\right.$ threshold $\leq 0.001$ ) or within $10,000 \mathrm{~kb}$ distance thereof, based on the 1000 Genomes reference panel, were clumped with the index SNPs, ${ }^{7}$ resulting in an initial set of 521 SNPs as genetic instrumental variables for the exposure.

\section{GWAS Summary Statistics for HD}

Genotype data for HD were obtained from the largest GWAS of residual age at onset recently published by the Genetic Modifiers of Huntington Disease (GeM-HD) Consortium. ${ }^{5}$ This GWAS included data on a total of 9,064 HD patients. The summary effect sizes for the outcome SNPs were based on the results of the continuous analysis as reported by the GeM-HD consortium. ${ }^{5}$ Residual age at onset was defined as the difference in years between observed and expected age at motor onset based on mutant CAG repeat size. ${ }^{5}$

\section{MR Analysis}

The MR analysis was performed using the TwoSampleMR package (version 0.5 .5 ) in $\mathrm{R}^{7}$ The SNPs were harmonized between the exposure and outcome data sets by removing SNPs with incompatible alleles as well as palindromic SNPs with intermediate allele frequencies $(n=176)$, resulting in a final set of 345 SNPs used for MR analysis (accounting for $3.55 \%$ of BMI variance). For calculating statistical power, from our previous study, we first estimated the SDs of BMI within 1 year of disease onset and the residual age at onset, which were $4.75 \mathrm{~kg} / \mathrm{m}^{2}$ and 8.10 years, respectively. ${ }^{3}$ With this information, we then estimated that the sample size for this MR analysis had a statistical power of $90 \%$ to detect a mean causal effect of BMI on residual age at onset of $\geq 3.8$ months per unit change of BMI (at a type I error rate of 0.05 and assuming no additional confounding after accounting for mutant CAG repeat size). ${ }^{8}$ We defined the results of the random-effects inverse-variance weighted method as our primary outcome. Horizontal pleiotropy was assessed by testing whether the intercept of the MR-Egger regression line significantly differed from zero, as well as with the MR pleiotropy residual sum and outlier (MR-PRESSO) test. ${ }^{9}$ In addition, we performed extensive sensitivity analyses, which included: (1) leave-one-out analyses; (2) alternative estimation methods using maximum likelihood, simple and weighted median and MR-Egger; and (3) robust MR methods, including mr-raps (as implemented in the mr-raps package version 0.3 .1 ) and the recently introduced contamination mixture method (as implemented in the MendelianRandomization package version 0.5 .0 ), which yield valid causal estimates even in the presence of some invalid 
Table Estimates of the Causal Effects of Genetically Determined BMI on Age at Onset in Huntington Disease

\begin{tabular}{|c|c|c|c|}
\hline Method & $\begin{array}{l}\text { Causal effect } \\
\text { estimate }^{a}\end{array}$ & $\begin{array}{l}\text { Confidence } \\
\text { interval }\end{array}$ & $p$ Value \\
\hline $\begin{array}{l}\text { Inverse variance } \\
\text { weighted }\end{array}$ & -0.33 & -1.22 to 0.56 & 0.47 \\
\hline Maximum likelihood & -0.33 & -1.17 to 0.51 & 0.44 \\
\hline Simple median & 0.20 & -1.08 to 1.48 & 0.76 \\
\hline Weighted median & -0.33 & -1.76 to 1.10 & 0.65 \\
\hline MR-Egger & -1.06 & -3.50 to 1.38 & 0.39 \\
\hline Robust MR & -0.33 & -1.18 to 0.51 & 0.44 \\
\hline $\begin{array}{l}\text { Contamination mixture } \\
\text { method }\end{array}$ & 0.16 & -1.43 to 1.75 & 0.81 \\
\hline
\end{tabular}

Abbreviations: $\mathrm{BMI}=$ body mass index; $\mathrm{MR}=$ mendelian randomization

${ }^{a}$ The units of the causal effect estimate are defined as years change in residual age at onset (i.e., after accounting for mutant CAG repeat size) per unit increase of genetically predicted BMI (years/BMI unit).

instrumental variables. ${ }^{10} p$ Values $<0.05$ were considered statistically significant.

\section{Data Availability}

GIANT/UK Biobank (portals.broadinstitute.org/collaboration/giant) and Gem-HD study (cegeme.partners.org/gem. euro.9k.html) summary statistics are freely available to qualified researchers. ${ }^{5,11}$

\section{Results}

The summary of the outcomes of the different MR methods is presented in the Table. The random-effects inverse-variance weighted overall causal effect of BMI on residual age at onset in $\mathrm{HD}$ was not statistically significant, i.e., a higher genetically determined BMI was not related to residual age at onset in $\mathrm{HD}(\beta=-0.33$ years per 1 -unit increase in BMI, confidence interval $[\mathrm{CI}]:-1.22$ to $0.56, p=0.47)$. All other complementary (nonparametric and robust) MR regression methods yielded comparable results (Table and Figure 1).

An overview of each single SNP's effect on residuals age at onset in $\mathrm{HD}$ is presented in eFigure 1 (links.lww.com/NXG/ A436). We did not find any indication for horizontal pleiotropy (Egger regression intercept $=0.01$ years, $\mathrm{CI}$ : -0.03 to $0.05, p=0.52$, Figure 1 ) or pleiotropic outliers (MR-PRESSO global test $p=0.054$ ). Furthermore, leave-one-out sensitivity analysis confirmed that the causal estimate was not disproportionately influenced by any single SNP (eFigure 2, links. lww.com/NXG/A437).

\section{Discussion}

Unintended progressive weight loss is frequently observed in $\mathrm{HD}$ and may even start many years before clinical onset. ${ }^{1} \mathrm{We}$ recently found that higher BMI is robustly associated with a slower rate of disease progression in $\mathrm{HD} .{ }^{3}$ Using data from the largest GWAS of age at onset in HD and taking advantage of recent advancements in MR analysis methods, which enable robust causal inference based on evaluation of the effects of genetic instrumental variables in different cohorts, here we demonstrate that $\mathrm{BMI}$ is unlikely to be causally related to age at onset in $\mathrm{HD}$, at least not to a clinically relevant degree.

Recently, we showed that about two-thirds of the determinants of age at onset and clinical progression in $\mathrm{HD}$ are similar. ${ }^{12}$ Given this large extent of overlap between age at onset and disease progression determinants in $\mathrm{HD},{ }^{12}$ our

Figure 1 Scatterplot of the Effect of Each Single Genetic Instrument on BMI and Residual Age at Onset

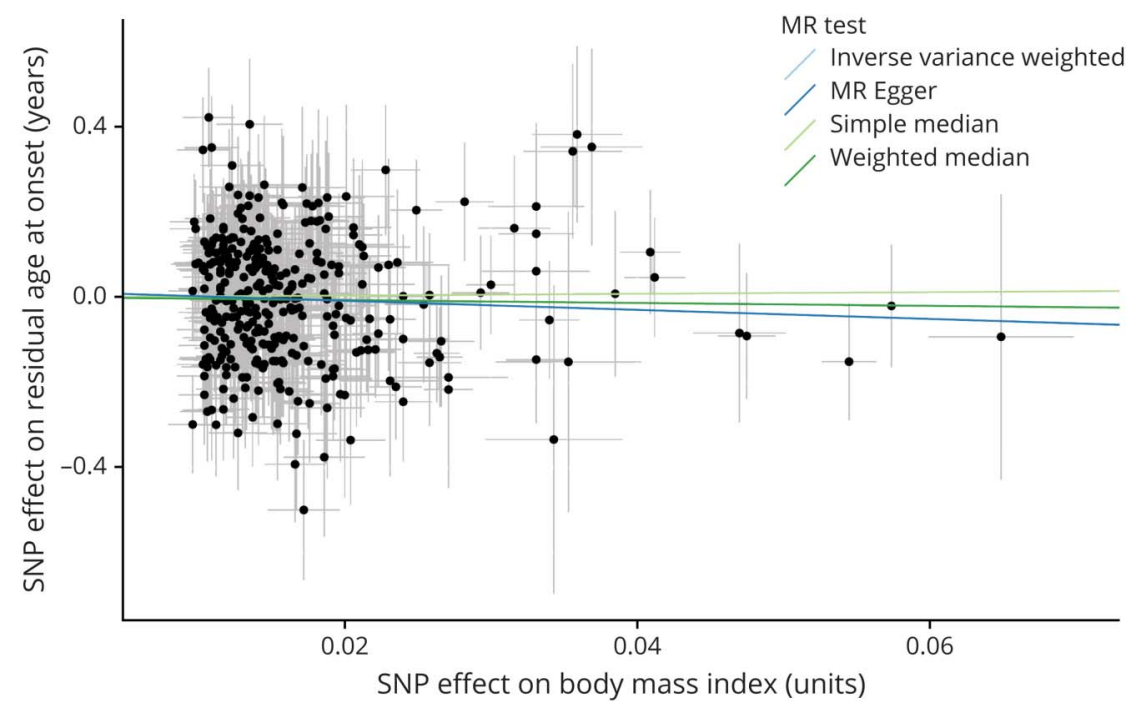

Each dot represents the combined effect of a single nucleotide polymorphism (SNP) on body mass index (BMI, horizontal axis) and residual age at onset in Huntington disease (vertical axis). The thin lines emanating from each dot represent the associated standard errors. Please note that all SNPs with a negative effect on BMI are shown to be positive with the sign of the effect on residual age at onset flipped. The causal association is represented by the slope of the regression lines for 4 representative mendelian randomization (MR) methods. All MR methods consistently indicated that there was not a causal effect of BMI on residual age at onset in Huntington disease. 
findings thus also suggest that a high body weight can be regarded as a marker rather than a cause of slow disease progression in HD. We did not, however, directly assess the effect of $\mathrm{BMI}$ on the rate of disease progression in patients with manifest disease, which therefore remains to be addressed in future studies. Nevertheless, our findings are well in line with a recent study in which it was shown that although transgenic HD mice on a leptin-deficient background displayed increased body weight, this did not result in amelioration of the extensive neuropathology. ${ }^{13}$ Similarly, a previous small-scale study did not find an effect of a high caloric intervention on disease progression in $\mathrm{HD}$ despite stabilization or increase of body weight in the majority of them. ${ }^{14}$ However, it remains to be elucidated whether other dietary interventions, especially fasting mimicking diets that have shown some efficacy in transgenic mouse models, ${ }^{15}$ would benefit patients with $\mathrm{HD}$.

Our results are of direct clinical relevance and indicate that the practice of actively promoting weight gain with the aim of delaying disease onset or slowing down disease progression in HD mutation carriers should be discouraged, especially given recent findings that metabolic disturbances like diabetes could in fact hasten disease onset. ${ }^{16}$ It is important though to stress that maintaining a healthy and stable body weight should remain a priority in $\mathrm{HD}$ mutation carriers because patients with $\mathrm{HD}$ are at an increased risk of malnutrition and cachexia, which are both associated with an increased risk of morbidity and mortality in general. ${ }^{1}$ The finding that BMI predicts disease progression but does not causally influence age at disease onset in patients with $\mathrm{HD}$ points to the existence of underlying pathologic processes that drive both the rate of clinical progression and weight loss in HD. These mechanisms may involve pathology of both central (hypothalamic/brain stem) and peripheral structures and need further elucidation as targeting these pathways, and not body weight per se, could be of therapeutic value. ${ }^{13,17-19}$

The MR paradigm has also been applied to assess the effect of $\mathrm{BMI}$ in other neurodegenerative diseases. Although BMI was not associated with the risk of developing Alzheimer disease, ${ }^{20}$ a recent study found that higher genetically determined BMI decreased the risk of developing Parkinson disease. ${ }^{21}$ However, given that Parkinson disease is commonly a disease of old age, survival bias might, at least partially, have confounded this latter finding. ${ }^{21}$

The main strength of our study is that it allows assessment of causality based on the application of the MR paradigm. However, despite consistent estimates among different MR tests and a range of sensitivity analyses to ensure compliance with the basic assumptions of MR analysis, we cannot definitely exclude all sources of bias, including weak and pleiotropic instrument bias, which is a challenge inherent to all $\mathrm{MR}$ studies. $^{4,7}$

\section{Acknowledgment}

The authors would like to thank all participants and researchers who were involved in the studies whose summary data were used, including the GIANT, UK Biobank, and GeM-HD studies. Furthermore, they are grateful to the GeMHD Consortium for making the GWAS summary statistics on the genetic determinants of age at onset in $\mathrm{HD}$ available for analysis.

\section{Study Funding}

No targeted funding reported.

\section{Disclosure}

The authors report no disclosures relevant to the manuscript. Go to Neurology.org/NG for full disclosures.

\section{Publication History}

Received by Neurology: Genetics March 4, 2021. Accepted in final form April 26, 2021.

Appendix Authors

\begin{tabular}{|c|c|c|}
\hline Name & Location & Contribution \\
\hline $\begin{array}{l}\text { Jorien M.M. van } \\
\text { der Burg, MD, } \\
\text { PhD }\end{array}$ & $\begin{array}{l}\text { Department of Public } \\
\text { Health and Primary Care, } \\
\text { Leiden University Medical } \\
\text { Centre, the Netherlands }\end{array}$ & $\begin{array}{l}\text { Drafting/revision of the } \\
\text { manuscript for content, } \\
\text { including medical writing } \\
\text { for content; major role in } \\
\text { the acquisition of data; } \\
\text { study concept or design; } \\
\text { and analysis or } \\
\text { interpretation of data }\end{array}$ \\
\hline $\begin{array}{l}\text { Patrick Weydt, } \\
\text { MD, PhD }\end{array}$ & $\begin{array}{l}\text { Department of } \\
\text { Neurodegenerative } \\
\text { Diseases and } \\
\text { Gerontopsychiatry, } \\
\text { University of Bonn, } \\
\text { Germany }\end{array}$ & $\begin{array}{l}\text { Drafting/revision of the } \\
\text { manuscript for content, } \\
\text { including medical writing } \\
\text { for content, and analysis } \\
\text { or interpretation of data }\end{array}$ \\
\hline $\begin{array}{l}\text { Georg Bernhard } \\
\text { Landwehrmeyer, } \\
\text { MD, PhD }\end{array}$ & $\begin{array}{l}\text { Department of } \\
\text { Neurology, Ulm University } \\
\text { Hospital, Germany }\end{array}$ & $\begin{array}{l}\text { Drafting/revision of the } \\
\text { manuscript for content, } \\
\text { including medical writing } \\
\text { for content, and analysis } \\
\text { or interpretation of data }\end{array}$ \\
\hline $\begin{array}{l}\text { N. Ahmad Aziz, } \\
\text { MD, PhD }\end{array}$ & $\begin{array}{l}\text { Department of } \\
\text { Neurology, University } \\
\text { Hospital Bonn, Germany }\end{array}$ & $\begin{array}{l}\text { Drafting/revision of the } \\
\text { manuscript for content, } \\
\text { including medical writing } \\
\text { for content; major role in } \\
\text { the acquisition of data; } \\
\text { study concept or design; } \\
\text { and analysis or } \\
\text { interpretation of data }\end{array}$ \\
\hline
\end{tabular}

\section{References}

1. Aziz NA, Roos RA. Characteristics, pathophysiology and clinical management of weight loss in Huntington's disease. Neurodegener Dis Manag. 2013;3(3):253-266.

2. Stan TL, Soylu-Kucharz R, Burleigh S, et al. Increased intestinal permeability and gut dysbiosis in the R6/2 mouse model of Huntington's disease. Sci Rep. 2020;10(1): 18270 .

3. van der Burg JMM, Gardiner SL, Ludolph AC, Landwehrmeyer GB, Roos RAC, Aziz NA. Body weight is a robust predictor of clinical progression in Huntington disease. Ann Neurol. 2017;82(3):479-483.

4. Davey Smith G, Hemani G. Mendelian randomization: genetic anchors for causal inference in epidemiological studies. Hum Mol Genet. 2014;23(R1):R89-R98.

5. Genetic Modifiers of Huntington's Disease (GeM-HD) Consortium. CAG repeat not polyglutamine length determines timing of Huntington's disease onset. Cell. 2019; 178(4):887-900.e14.

6. Locke AE, Kahali B, Berndt SI, et al. Genetic studies of body mass index yield new insights for obesity biology. Nature. 2015;518(7538):197-206

7. Hemani G, Zheng J, Elsworth B, et al. The MR-base platform supports systematic causal inference across the human phenome. eLife. 2018;7:e34408. 
8. Brion MJA, Shakhbazov K, Visscher PM. Calculating statistical power in Mendelian randomization studies. Int J Epidemiol. 2012;42(5):1497-1501.

9. Verbanck M, Chen CY, Neale B, Do R. Detection of widespread horizontal pleiotropy in causal relationships inferred from Mendelian randomization between complex traits and diseases. Nat Genet. 2018;50(5):693-698.

10. Burgess S, Foley CN, Allara E, Staley JR, Howson JMM. A robust and efficient method for Mendelian randomization with hundreds of genetic variants. Nat Commun. 2020; 11(1):376.

11. Yengo L, Sidorenko J, Kemper KE, et al. Meta-analysis of genome-wide association studies for height and body mass index in approximately 700000 individuals of European ancestry. Hum Mol Genet. 2018;27(20):3641-3649.

12. Aziz NA, van der Burg JM, Tabrizi SJ, Landwehrmeyer GB. Overlap between age-atonset and disease progression determinants in Huntington disease. Neurology. 2018; 90(24):e2099-e2106.

13. Sjogren M, Soylu-Kucharz R, Dandunna U, et al. Leptin deficiency reverses high metabolic state and weight loss without affecting central pathology in the R6/2 mouse model of Huntington's disease. Neurobiol Dis. 2019;132:104560.

14. Trejo A, Boll MC, Alonso ME, Ochoa A, Velasquez L. Use of oral nutritional supplements in patients with Huntington's disease. Nutrition. 2005;21(9):889-894.
15. Duan W, Guo Z, Jiang H, Ware M, Li XJ, Mattson MP. Dietary restriction normalizes glucose metabolism and BDNF levels, slows disease progression, and increases survival in huntingtin mutant mice. Proc Natl Acad Sci USA. 2003;100(5):2911-2916.

16. Ogilvie AC, Gonzalez-Alegre P, Schultz JL. Diabetes mellitus is associated with an earlier age of onset of Huntington's disease. Mov Disord. 2021;36(4):1033-1034.

17. Cheong RY, Gabery S, Petersén $\AA$. The role of hypothalamic pathology for non-motor features of Huntington's disease. J Huntingtons Dis. 2019;8(4):375-391.

18. van Wamelen DJ, Aziz NA, Roos RA, Swaab DF. Hypothalamic alterations in Huntington's disease patients: comparison with genetic rodent models. J Neuroendocrinol. 2014;26(11):761-775.

19. van der Burg JM, Bjorkqvist M, Brundin P. Beyond the brain: widespread pathology in Huntington's disease. Lancet Neurol. 2009;8(8):765-774.

20. Nordestgaard LT, Tybjærg-Hansen A, Nordestgaard BG, Frikke-Schmidt R. Body mass index and risk of Alzheimer's disease: a Mendelian randomization study of 399,536 individuals. J Clin Endocrinol Metab. 2017;102(7):2310-2320.

21. Noyce AJ, Kia DA, Hemani G, et al. Estimating the causal influence of body mass index on risk of Parkinson disease: a Mendelian randomisation study. PLoS Med. 2017;14(6):e1002314. 


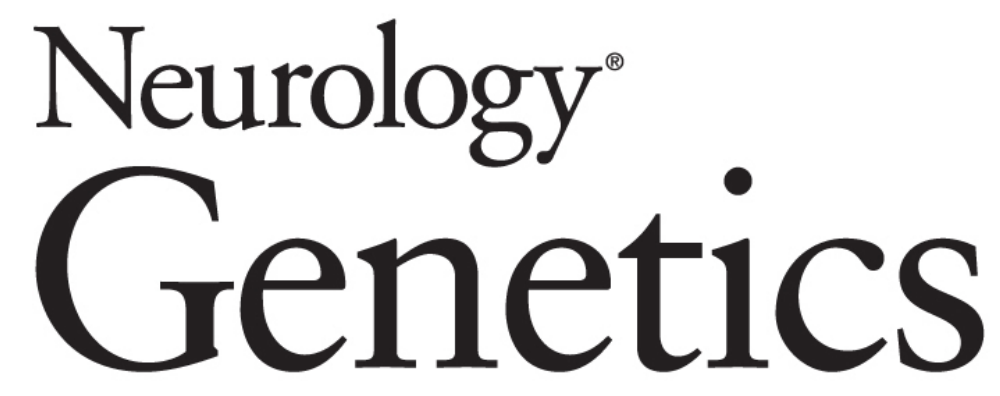

\section{Effect of Body Weight on Age at Onset in Huntington Disease: A Mendelian Randomization Study}

Jorien M.M. van der Burg, Patrick Weydt, Georg Bernhard Landwehrmeyer, et al. Neurol Genet 2021;7;

DOI 10.1212/NXG.0000000000000603

\section{This information is current as of July 6, 2021}

\section{Updated Information \& Services}

References

Citations

Subspecialty Collections

Permissions \& Licensing

Reprints including high resolution figures, can be found at: http://ng.neurology.org/content/7/4/e603.full.html

This article cites 21 articles, 1 of which you can access for free at: http://ng.neurology.org/content/7/4/e603.full.html\#\#ref-list-1

This article has been cited by 1 HighWire-hosted articles: http://ng.neurology.org/content/7/4/e603.full.html\#\#otherarticles

This article, along with others on similar topics, appears in the following collection(s):

Association studies in genetics

http://ng.neurology.org//cgi/collection/association_studies_in_genetics Huntington's disease

http://ng.neurology.org//cgi/collection/huntingtons_disease

Information about reproducing this article in parts (figures,tables) or in its entirety can be found online at:

http://ng.neurology.org/misc/about.xhtml\#permissions

Information about ordering reprints can be found online: http://ng.neurology.org/misc/addir.xhtml\#reprintsus

Neurol Genet is an official journal of the American Academy of Neurology. Published since April 2015, it is an open-access, online-only, continuous publication journal. Copyright Copyright @ 2021 The Author(s). Published by Wolters Kluwer Health, Inc. on behalf of the American Academy of Neurology.. All rights reserved. Online ISSN: 2376-7839.

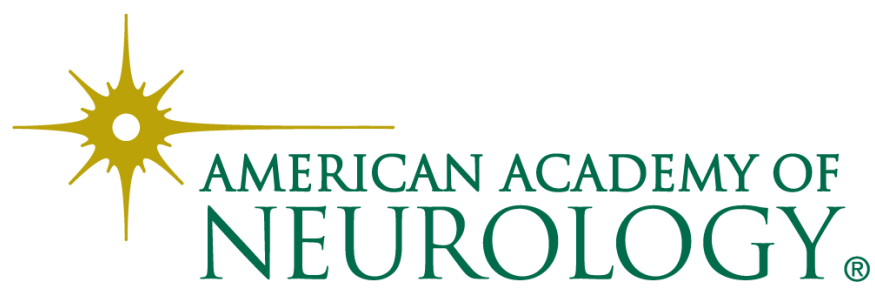

